\title{
Ruben Araujo de Mattos: uma homenagem
}

\section{| ${ }^{1}$ Tatiana Wargas Baptista |}

1 Instituto de Medicina Social - Universidade do Estado do Rio de Janeiro, Rio de Janeiro-RJ, Brasil (twargas@gmail.com) ORCID: 0000-0002-3445-2027

DOI: http://dx.doi.org/10.1590/S0103-73312021310200

Ruben Araujo de Mattos foi professor do Instituto de Medicina Social da Universidade do Estado do Rio de Janeiro por 35 anos (1985-2020). Este Editorial é uma homenagem a esse professor que faleceu em 25 de dezembro de 2020 deixando um legado de contribuições e ensinamentos para a formação em saúde coletiva. Suas aulas, produçóes e registros espalham-se pelo campo afora e se multiplicam em novas falas e produçóes daqueles que entraram em contato direto com ele ou com seus escritos.

Ruben foi ledor, parecerista e entusiasta da Revista Physis - a Revista da Saúde Coletiva, e fazia questão de ressaltar a diferença deste periódico em relação aos demais só por trazer desde o seu nome o convite à saúde coletiva. Recomendava sempre que podia a leitura do texto de Joel Birman, A Physis da Saúde Coletiva, que abre o primeiro número da Revista em 1991. Um texto curto e divisor de águas ao apresentar a saúde coletiva como um campo multidisciplinar que "admite no seu território uma diversidade de objetos e de discursos teóricos, sem reconhecer em relação a eles qualquer perspectiva hierárquica e valorativa" (Birman, 1991: 15).

Esse texto era uma inspiração para Ruben porque possibilitava unir o debate epistêmico da saúde coletiva com a construção de novas políticas e práticas em saúde. 
Como médico, Ruben acumulava reflexôes sobre a clínica desde sua formação no início da década de 1980. Foi a partir do contato com o texto de Ivan Illich, A Expropriação da Saúde: Nêmesis da Medicina, durante a residência em clínica médica e do encontro com Hésio Cordeiro ${ }^{1}$, que suas inquietações com relação à prática médica o levaram a buscar em 1984 o mestrado em Saúde Coletiva no Instituto de Medicina Social da Universidade do Estado do Rio de Janeiro - IMS/ Uerj. O cenário era de construção das bases do Sistema Único de Saúde numa conjuntura política de disputa por um novo projeto para o país. O IMS era palco de debates acalorados da política de saúde e muitos quadros acadêmicos estavam engajados na tarefa de operar as transformaçóes concretas da saúde.

Foi nesse contexto que Ruben se engajou numa linha importante de investigação e produção de conhecimento no campo da saúde coletiva: o planejamento em saúde, e iniciou o estudo de mestrado sobre o método CENDES/OPAS, sob orientação de José Luiz Fiori. Nesse mergulho ele adentrou no reconhecimento da história do planejamento em saúde na América Latina (Mattos, 1988).

No decorrer do mestrado, Ruben prestou concurso para professor do Instituto e ingressou em 1985 no Departamento de Política, Planejamento e Administração em Saúde. Assumiu, com diferentes parcerias, a disciplina de Planejamento em Saúde (de 1985 a 2020) e consolidou um conhecimento apurado sobre as origens e o desenvolvimento do planejamento em saúde, visto como um campo de saber no contexto do planejamento econômico para o desenvolvimento na América Latina. A partir dessa lente, Ruben enfatizava as estratégias políticas e os modos de operar politicamente na discussão do planejamento em saúde, ensinando a pensar SOBRE o planejamento, QUANDO e PORQUE se mobiliza o planejar, muito mais na intenção de reconhecer ferramentas que podem ajudar nas situações concretas e orientar as açóes políticas do que ensinar os métodos de planejamento propriamente ditos. Desse modo, seus alunos aprendiam a pensar planejamento e política como parte de um mesmo jogo a ser compreendido e jogado na relação com a economia e com os diferentes atores sociais.

Em sua tese de doutorado, desenvolvida entre 1996 e 2000, Ruben adentra um pouco mais na análise de políticas e desenvolve um estudo sobre a elaboraçáo de propostas de políticas de saúde no âmbito do Banco Mundial. Sua análise da política faz um convite à reflexão sobre os processos e os poderes presentes nas estratégias adotadas pelo Banco e, com uma leitura construcionista e pragmática da ciência, 
segue um caminho de pesquisa que busca nos indícios, nas mediaçôes políticas e na retórica, os argumentos que sustentam a oferta de novas ideias de políticas de saúde pelas agências internacionais para os países (Mattos, 2000).

Seu estudo de doutorado foi um mergulho na análise de políticas, mas também foi mais uma imersão na história e filosofia da ciência. Neste momento, Ruben aguça seu olhar teórico-metodológico para a análise de política e para as práticas em saúde, pensando-as de forma cada vez mais relacional.

Mas, sobre a prática em saúde, sua entrada no Instituto o levou também a manter-se vinculado desde o primeiro momento ao mundo da atenção à saúde. Assumiu atividades docentes na Residência em Medicina Preventiva e Social e neste campo de práticas, o planejamento e a programação eram ferramentas que deveriam ser cotidianamente inventadas, como estratégias para enfrentamento dos problemas e questóes concretas do dia a dia do atendimento em saúde. Dessa experiência e também das conversas com parceiras/parceiros, orientandos e alunos da graduação (na disciplina de Funsaco - Fundamentos da Saúde Coletiva), da residência, do mestrado e doutorado, Ruben acumulou reflexões sobre as práticas e o cuidado em saúde.

Numa parceria com Roseni Pinheiro constituiu no ano 2000 o Lappis Laboratório de Pesquisa Sobre Práticas de Integralidade em Saúde - e partilhou em inúmeros textos, aulas e conferências, ministradas presencialmente e remotamente (como nos últimos anos), ideias e questôes relativas à prática e ao cuidado em saúde.

Seu texto certamente mais lido e discutido em graduaçóes e pós-graduaçóes da saúde foi o que abordou os sentidos da integralidade, publicado em 2001 (Mattos, 2001). Neste texto, Ruben apresenta três grandes sentidos para o princípio/diretriz da integralidade.

A integralidade como um traço da boa medicina, num uso prudente do conhecimento biomédico sobre a doença, mas sobretudo num uso guiado por uma visão abrangente das necessidades dos sujeitos que tratamos, ressaltando que a integralidade deve ser incorporada como um valor que merece ser defendido em relação a todas as práticas de saúde.

Um segundo sentido de integralidade como modo de organizar as práticas em programas integrais, como um princípio de organização contínua do processo de trabalho nos serviços de saúde. 
E a integralidade como políticas específicas voltadas a certos problemas de saúde ou necessidades de certos grupos específicos, visando abarcar os diversos grupos, respeitando suas especificidades.

Nesta discussão, Ruben adentrou o tema do cuidado e da formação em saúde e inspirado nas leituras de Boaventura de Sousa Santos propôs o debate sobre o cuidado prudente para uma vida decente (Mattos, 2004).

Em 2008, iniciou o projeto Construindo Caminhos para Análise de Políticas de Saúde, a partir do diálogo com parceiras/parceiros, orientadas/orientandos que realizavam estudos de políticas e práticas em saúde, levando a produção de um site (http://ccaps.ims.uerj.br/) para diálogo e divulgação de debates, encontros, oficinas e estudos sobre políticas e um livro reunindo contribuiçôes sobre diferentes Caminhos para Análise de Políticas de Saúde (Mattos e Baptista, 2015). Em mais de dez anos de existência Caminhos se constituiu no espaço de acolhida, diálogo, troca entre professores e alunos em formação, um espaço para pensar os modos de produzir pesquisas no campo da saúde coletiva com o foco nas políticas e práticas em saúde.

Mas também nesse percurso dois temas atraíram atenção especial de Ruben: a Política de Educação Permanente em Saúde e a Política de Alimentação e Nutrição e SAN. Ambas vinham sendo estudadas em projetos específicos e parcerias constituídas. Mas no caso da Política de Alimentação e Nutrição e SAN, o encontro com sua companheira Rosana Salles significou também novas aproximaçóes e caminhos na própria saúde coletiva, intensificando reflexôes juntamente com a área de epidemiologia.

Por fim, é importante mencionar algo que Ruben sempre lembrava com muito orgulho e carinho. Seus olhos sorriam para dizer que sua formação foi feita toda na UERJ, do ensino fundamental no Colégio de Aplicação, passando pela Medicina, ao doutorado no IMS. Participou e contribuiu ativamente em todos os âmbitos de discussão desta instituiçáo. Viveu e alimentou a UERJ com suas ideias e intervençôes, com sua empolgação em travar debates - nas aulas, orientaçóes, no Conselho Universitário, Comissóes, grupos de trabalho, seleçóes e como Diretor do Instituto de Medicina Social entre os anos de 2004 a 2007. Ruben sustentou e defendeu a UERJ, a Universidade e educação pública, a saúde, o SUS, em cada ação e gesto cotidianos. 
Homenagear Ruben é lembrar da importância da Educação e da Saúde no Brasil. Ruben não se furtava ao debate e chamava para o diálogo honesto e respeitoso, clamando pela defesa de valores e princípios em favor de uma vida decente, sempre exercendo o pensamento crítico e minucioso dos fatos e questóes que afetam nossas vidas.

Essa homenagem é dedicada a família de Ruben, mas de forma específica as suas filhas queridas e amadas. Que guardem a lembrança da grandeza do pai que tiveram e o quanto ele fez diferença nesse mundo. Que fiquem com os momentos bons, com as estórias e ensinamentos compartilhados; que lembrem da importância do brilho nos olhos como um guia para seguir caminhando na vida e lutando por uma vida melhor e mais feliz para todas e todos.

\section{Referências}

Birman, Joel. A Physis da Saúde Coletiva. Physis - Revista da Saúde Coletiva. V.1, n.1, 1991. P.7-11.

Illich, Ivan. A expropriação da Saúde: Nêmesis da Medicina. Rio de Janeiro, Ed.Nova Fronteira, 1975.

Mattos, Ruben Araujo de. A teoria da programaçào de saúde no método CENDES/OPAS. Rio de Janerio, Dissertação de Mestrado, IMS/Uerj, 1988.

Mattos, Ruben Araujo de. Desenvolvendo e ofertando idéias: um estudo sobre a elaboração de propostas de política de saúde no âmbito do Banco Mundial. Rio de Janerio, Dissertaçáo de Mestrado, IMS/Uerj, 2000.

Mattos, Ruben Araujo de. Os sentidos da integralidade: algumas reflexôes acerca de valores que merecem ser defendidos. In: Mattos, Ruben Araujo de; Pinheiro, Roseni (org). Os sentidos da integralidade na atenção e no cuidado à saúde. 1ed. Rio de Janeiro: UERJ, IMS: ABRASCO, 2001. p.39-64.

Mattos, Ruben Araujo de. Cuidado prudente para uma vida decente. In: Pinheiro, Roseni; Mattos, Ruben A. (Org.). Cuidado: as Fronteiras da Integralidade. 1ed. São Paulo: HUCITEC, 2004, v.1, p. 119-132.

Mattos, Ruben Araujo de; Baptista, Tatiana Wargas de. Caminhos para análise de políticas de saúde. 1. ed. Porto Alegre: Rede UNIDA, 2015. v.1. p.509. 
Aproveitamos para enfatizar o caráter também coletivo das publicações científicas e agradecer a colaboração dos pareceristas que generosamente contribuíram com seu tempo e sua expertise para viabilizar esta edição publicada e cujos nomes vêm abaixo em ordem alfabética.

Amanda Ornela

Ana Carolina Feldenheimer

Ana Paula Remmi

Berenice Temoteo da Silva

Bianca Leandro

Cecília Soares

Charles Tesser

Cristiane Silvestre de Paula

Erika Tomaz

Fabiana Pires

Fátima Cecchetto

Fatima Roquete

Francini Guizardi

Frederico Policarpo

Leila Maia

Lucas Tramontano

Luciane Guerra

Luiz Augusto Souza

Luiza Costa

Marcia Agostini

Márcia Alves

\author{
Marcilio Dantas Brandão \\ Maria Claudia Carvalho \\ Maria Cristina Couto \\ Maria Eduarda Moraes \\ Maria Lúcia Bosi \\ Maria Marta Amorim \\ Mariana Bteshe \\ Michele Cecille \\ Neuma Chaveiro \\ Pablo Rocon \\ Patrícia Tavares Ribeiro \\ Paula Cerqueira \\ Paula Gaudenzi \\ Paula Land \\ Rogerio Azize \\ Rosa Rocha \\ Suzana Canez \\ Valeska Zanello \\ Vanessa Rangel \\ Wagner Carmargo \\ Washington Castilhos
}

\section{Nota}

${ }^{1}$ Professor da medicina e importante sanitarista tendo participado da idealização e criação do Instituto de Medicina Social no início da década de 1970. Hésio também faleceu no ano de 2020 deixando um legado importante para a saúde coletiva e o SUS. O próximo número da Physis trará um dossiê sobre Hésio e sua luta pela saúde pública no Brasil. 